\title{
Effects of fast neutrons on the eye
}

\author{
JOHN ROTH, NICHOLAS BROWN, MARY CATTERALL, AND \\ ANTHONY BEAL \\ From the MRC Cyclotron Unit, Hammersmith Hospital, London
}

This report describes the ophthalmic examination of patients receiving $7.5 \mathrm{MeV}$ fast neutrons for the treatment of advanced tumours of the head in which the eye was unavoidably irradiated. The treatment was given by the Medical Research Council's cyclotron, and details have been published (Catterall and Vonberg, 1974; Catterall, Sutherland, and Bewley, 1975). A preliminary report on the effects of neutron irradiation on the eye has also been completed (Brown, Roth, Catterall, and Beal, 1976). The present paper does not include any observations on changes which are known to be produced by doses of $x$ or gamma radiation for the treatment of similar tumours.

\section{Patients and methods}

All patients receiving neutron therapy to the head and neck were accepted for study. A total of 93 eyes were examined in patients ranging in age from 26 to 82 years, with a follow-up period of 10 weeks to 31 months from the beginning of treatment.

\section{Neutron therapy}

The dose of radiation received by the eye was determined by detailed planning. The dose of $7.5 \mathrm{MeV}$ fast neutrons received by the patients ranged from 0 to 1620 rads given in 12 treatments during a period of 26 to 33 days.

\section{Ophthalmic examination}

The symptoms and signs found on ophthalmic examination were scored in intensity on a scale of 0 to 4 . The eye was examined in detail and observations quantified for analysis. Colour macrophotography was used to record superficial signs and slit-image photography to record the lens of the eye (Brown, 1972). The patients were examined before treatment when possible and thereafter at first weekly, then monthly, and later at longer intervals.

\section{Results}

The length of follow-up was not enough to include all possible late complications but we consider

Address for reprints: N. Brown, Department of Experimental Uphthalmology, Institute of Ophthalmology, Judd Street, London WCrH 9QS that some examples of all likely late ones were seen.

\section{PRE-EXISTING OCULAR DISEASE}

Patients with neoplasia are often elderly and show senile and degenerative ocular changes. Since the tumour is near to the eye it may itself disturb the eye either directly or indirectly by affecting nerves or vessels supplying the eye. Pre-existing symptoms and signs were recorded and subtracted from the results.

The tumour directly obstructed naso-lacrimal drainage in three patients and caused proptosis in three. The cranial nerves of ophthalmic importance were involved in three patients with optic atrophy. In one patient the fifth cranial nerve was destroyed with resultant corneal anaesthesia, which may have predisposed to subsequent corneal ulceration. The onset of all symptoms reported is given in days, weeks, and months from the first day of treatment.

\section{CLINICAL EFFECTS-SYMPTOMS (Table I)}

\section{Visual acuity}

Blurred vision commonly occurred after 14 to 28 days, although it was a late symptom in some patients. It tended to remit in most eyes after some months but it persisted in those that had received 500 rads or more. At levels of 1500 rads or more vision deteriorated progressively. Measurement of visual acuity confirmed the patient's own observations. A reduction of one or two lines on the test chart was usual in patients with transient symp-

Table I Percentage incidence and nature of ophthalmic symptoms in 93 eyes related to radiation dose

\begin{tabular}{|c|c|c|c|c|c|}
\hline \multirow[b]{2}{*}{ Symptom } & \multicolumn{5}{|c|}{ Radiation dose (rads) } \\
\hline & $\begin{array}{l}0-100 \\
(n=28)\end{array}$ & $\begin{array}{l}101-300 \\
(n=28)\end{array}$ & $\begin{array}{l}301-500 \\
(n=13)\end{array}$ & $\begin{array}{l}501-1000 \\
(n=8)\end{array}$ & $\begin{array}{r}>1000 \\
(n=16)\end{array}$ \\
\hline Blurring of vision & 18 & 29 & 54 & 50 & 81 \\
\hline $\begin{array}{l}\text { Eyelid discomfort } \\
\text { Eye discomfort }\end{array}$ & $\overline{7}$ & $\begin{array}{l}29 \\
32\end{array}$ & $\begin{array}{l}62 \\
38\end{array}$ & $\begin{array}{l}38 \\
38\end{array}$ & $\begin{array}{l}69 \\
75\end{array}$ \\
\hline Epiphora & 10 & 46 & 62 & 63 & 61 \\
\hline
\end{tabular}


toms, but in high dose (1500 rads) vision was reduced below $6 / 60$ permanently in most patients. The reduction in visual acuity correlated in time and severity with corneal changes, which are described later.

\section{Pain}

Thirty-two patients complained of discomfort in the eyelids beginning after 20-34 days, and later in patients with conjunctival keratinization. Thirty patients complained of pain or discomfort in the eye, as early as 27 days in one patient and as late as five months in another. The average time of onset was at ro weeks. Severe and persistent pain occurred in most patients receiving more than 1000 rads. Discomfort in the eye correlated with epithelial keratitis recorded as ++ or greater, and pain with corneal erosion in three eyes and corneal ulceration in four.

\section{Epiphora}

Epiphora occurred in 31 eyes after 8 to 19 weeks. In three eyes it was present initially and was aggravated after neutron therapy. Epiphora was transient in low-dose patients, remitting at about 12 weeks and persisting in only 13 eyes. The causes of epiphora are considered later.

\section{CLINICAL EFFECTS-SIGNS}

\section{Skin erythema (Table II, Fig. I)}

Erythema of the face and eyelids occurred in 52 patients seen during the early weeks of treatment. Four patients were not examined during the appropriate period. The reaction was seen as early as 15 days, reaching a peak at 25 days, and there-
Table II Percentage incidence and nature of signs occurring in the face, eyelids, and lacrimal system related to radiation dose

\begin{tabular}{|c|c|c|c|c|c|}
\hline \multirow[b]{2}{*}{ Sign } & \multicolumn{5}{|c|}{ Radiation dose (rads) } \\
\hline & $\begin{array}{l}\leqslant 100 \\
(n=28)\end{array}$ & $\begin{array}{l}101-300 \\
(n=28)\end{array}$ & $\begin{array}{l}301-500 \\
(n=13)\end{array}$ & $\begin{array}{l}501-1000 \\
(n=8)\end{array}$ & $\begin{array}{l}>1000 \\
(n=16)\end{array}$ \\
\hline Erythema of face & 32 & 54 & 77 & 100 & 69 \\
\hline Erythema of lids & 7 & 54 & 77 & 88 & 56 \\
\hline Oedema of lids & 10 & 25 & 77 & 73 & 75 \\
\hline \multicolumn{6}{|l|}{ Mucopurulent } \\
\hline discharge & $4^{*}$ & 25 & 54 & 75 & 63 \\
\hline Loss of cilia & 10 & 29 & 85 & 50 & 81 \\
\hline \multicolumn{6}{|l|}{ Meibomian } \\
\hline obstruction & 10 & 32 & 69 & 50 & 88 \\
\hline \multirow{2}{*}{\multicolumn{6}{|c|}{ Distortion of lid }} \\
\hline & & & & & \\
\hline contour & 7 & 36 & 38 & 50 & 75 \\
\hline Punctal ectropion & 10 & 25 & 23 & 38 & 50 \\
\hline Tear fluid excess & 18 & 46 & 46 & 50 & 69 \\
\hline \multicolumn{6}{|l|}{ Tear fluid } \\
\hline deficiency & 7 & 18 & 15 & $13^{*}$ & 44 \\
\hline Precorneal drying & $4^{*}$ & I I & 23 & 50 & $3 \mathbf{I}$ \\
\hline Oil excess & 14 & 36 & 38 & 25 & $3 \mathbf{I}$ \\
\hline Oil deficiency & - & 18 & 46 & 25 & 56 \\
\hline Mucus excess & 18 & 36 & 62 & 63 & 88 \\
\hline Debris excess & 21 & 39 & 69 & 63 & 88 \\
\hline
\end{tabular}

*Only one eye affected

after subsiding to disappear at ro-12 weeks. In no case did erythema persist, but it was followed later in some patients by telangiectasia and in two by increased skin pigmentation.

\section{Eyelids (Table II, Fig. I)}

Oedema. This was seen in 37 eyes and coincided with the appearance and subsidence of the erythematous response, but when an eyelid received a dose of over rooo rads it persisted and in some cases increased.

Loss of cilia. Partial or complete loss of cilia was

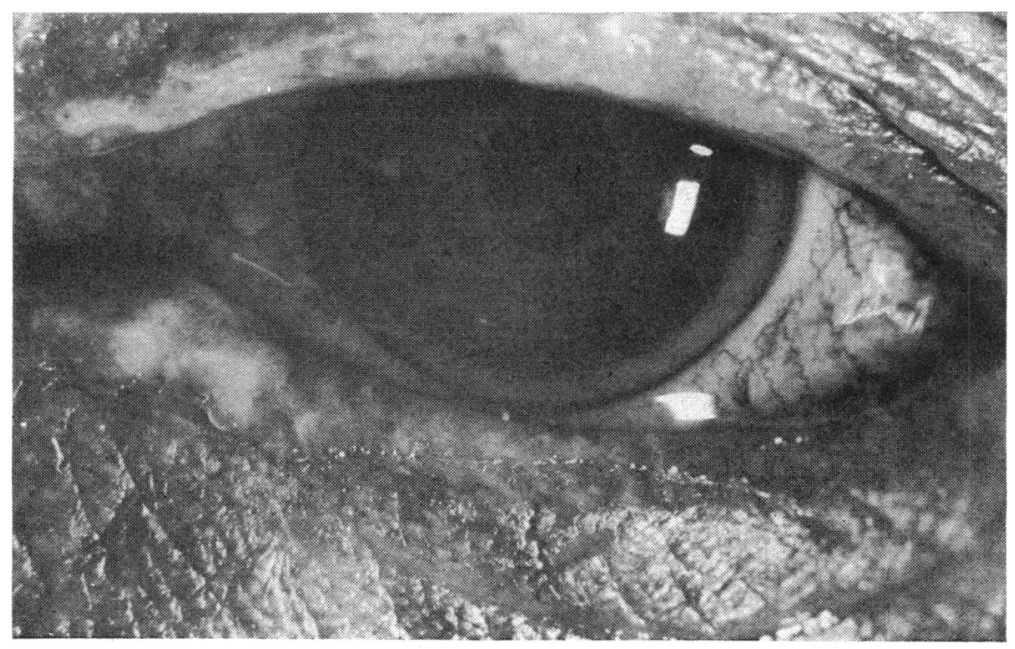

FIG. I Eye at 35 days shozving skin and conjunctival erythema, skin oedema, loss of cilia, distortion of lid margin contour, mucopurulent discharge, and excessive tear fluid in marginal gutter 
common. Reduction in the number of lashes occurred between 22 days and eight weeks with complete loss by 30 days to 19 weeks. In only two patients was there any regrowth.

Distortion of lid contour. Rounding of the posterior edge resulting in imperfect lid apposition to the globe occurred in 33 eyes. This distortion appeared between 18 and 49 days, tended to persist, and disappeared in only one patient. The amount of distortion paralleled that of the oedema and increased later ( 19 weeks to five months) in patients in whom the oedema increased.

Meibomian gland obstruction. Obliteration of meibomian orifices occurred in 39 eyes. It was first seen after 15 to 34 days and tended partially to remit later. It was associated with absence of the oily layer of the tear film. In late cases (after four months) accumulation of secretion was seen through the conjunctiva in some tarsal glands which had not reopened.

Mucopurulent discharge. This commonly collected along the lower lid margin and at the inner canthus in spite of the routine use of antibiotic drops. It was thought to be due to abnormal tear film constituents rather than infection. All cultures were sterile and microscopy showed that the constituent cells were leucocytes.

\section{Lacrimal function (Table II)}

Lacrimal punctal stenosis. Partial punctal obstruction developed in 27 eyes after 17 to 34 days and progressed to become complete in II cases. In the less affected cases partial remission occurred by 5 months.

Lacrimal punctal ectropion. Ectropion occurred in 24 eyes after 18 days to 12 weeks. The condition tended to remit when lid oedema subsided but persisted to some extent in most cases.

Naso-lacrimal duct obstruction. This occurred bilaterally in two patients at 19 months, probably as a result of radiation. Uncomplicated bilateral dacryocystorhinostomies were performed with relief of symptoms in one patient.

Tear fluid. This was seen in excess in 39 eyes after 15 days to 12 weeks and tended to persist (Fig. I). Seventeen eyes developed a deficiency with onset of corneal drying between $3^{8}$ days and 13 weeks, which tended to persist.

Tear film constituents. There was excessive oil in the tears in 25 eyes between six days and 15 weeks with return to normal in 11 to 19 weeks or progression to deficiency in 22 eyes. Mucus was excessive in 42 eyes after 18 days to 15 weeks and persisted. Excess debris of a fine, white cellular appearance was observed in the tear film in 46 eyes after 14 to 38 days with subsequent disappearance at 20 weeks. Microscopy showed it to consist of leucocytes and in one case also erythrocytes.

\section{Conjunctiva (Table III)}

Conjunctival injection (Fig. I). Injection was observed in 40 eyes. There was dilatation of the arterioles, capillaries, and venules, particularly in the tarsal conjunctiva. The global conjunctiva was less affected. Injection was first observed at I3 days, reached a peak at 27 days, and thereafter subsided slowly. The course paralleled that of the skin erythema but the decline seemed to take longer and result in a pathologically pale appearance. The pallor was due to a relative absence of blood-filled capillaries; the arterioles appeared relatively normal at this stage.

Telangiectasis (Fig. 2). Telangiectasis was seen in 26 eyes on average at 25 weeks, and in all cases had been preceded by a significant degree of erythema $(++$ to ++++$)$. Differentiation between injection and telangiectasis was not always easy. Telangiectasis was recognized as dilated arterioles, straight in the tarsal conjunctiva and tortuous on the bulbar conjunctiva, from which normal or enlarged capillaries branched at right-angles.

Oedema. Chemosis was seen in 17 eyes from 18 days onwards and occurred only in association with moderate or severe $(++$ to ++++$)$ erythema. The oedema subsided by 43 days, except in one severe case in which it persisted.

Table III Percentage incidence and nature of signs occurring in the conjunctiva and cornea related to radiation dose

\begin{tabular}{|c|c|c|c|c|c|}
\hline \multirow[b]{2}{*}{ Sign } & \multicolumn{5}{|c|}{ Radiation dose (rads) } \\
\hline & $\begin{array}{l}\leqslant 100 \\
(n=28)\end{array}$ & $\begin{array}{l}101-300 \\
(n=28)\end{array}$ & $\begin{array}{l}301-500 \\
(n=13)\end{array}$ & $\begin{array}{l}501-1000 \\
(n=8)\end{array}$ & $\begin{array}{l}>1000 \\
(n=16)\end{array}$ \\
\hline \multirow{9}{*}{$\begin{array}{l}\text { Conjunctival } \\
\text { injection } \\
\text { Conjunctival } \\
\text { oedema } \\
\text { Conjunctival ulcer } \\
\text { Telangiectasia } \\
\text { Keratin formation } \\
\text { Contracture } \\
\text { Corneal erosion } \\
\text { Epithelial keratitis } \\
\text { Reduction of } \\
\text { corneal sensation }\end{array}$} & $4^{*}$ & 50 & 77 & 75 & 69 \\
\hline & $4^{*}$ & 14 & 46 & 38 & 50 \\
\hline & - & - & - & - & 13 \\
\hline & 10 & 25 & $8^{*}$ & 50 & 50 \\
\hline & $4^{*}$ & 7 & $8^{*}$ & 25 & 38 \\
\hline & $4^{*}$ & $4^{*}$ & 15 & - & 13 \\
\hline & - & - & 23 & $13^{*}$ & 31 \\
\hline & 7 & 36 & 46 & 38 & 63 \\
\hline & $4^{*}$ & 18 & 15 & 25 & 50 \\
\hline
\end{tabular}




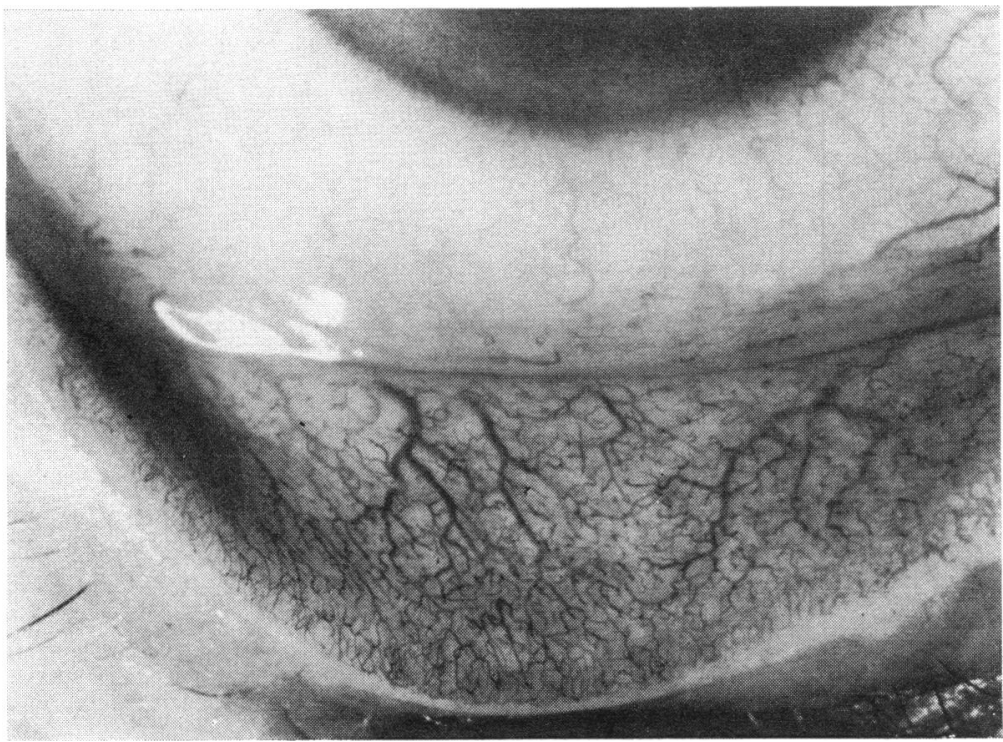

FIG. 2 Telangiectasia of tarsal conjunctiva

Ulceration. This was seen in only two patients in association with other notable signs of radiation. The conjunctiva of the lower fornix was affected in both and the global conjunctiva also in one patient. It occurred relatively late, after I I weeks.

Contracture. Contracture of the conjunctiva was a relatively late sequel in six eyes after 13 weeks.

Keratinization (Fig. 3). Keratin plaques appeared after Io weeks in 12 eyes on the tarsal conjunctiva near the lid margins and occasionally encroached on the global conjunctiva. They tended to vary in size and position from one examination to the next. In three eyes they disappeared and were replaced by normal epithelium.

\section{Cornea (Table III)}

Epithelial keratitis. Punctate epithelial keratitis of minor degree was a common finding and caused slight loss of visual acuity and discomfort. It occurred in 32 eyes after 15 days, reached a peak at 30 days, and thereafter declined slowly with complete healing after ro weeks in most eyes but with some degree of persistence in others.

Corneal erosion (Fig. 4). Epithelial keratitis was

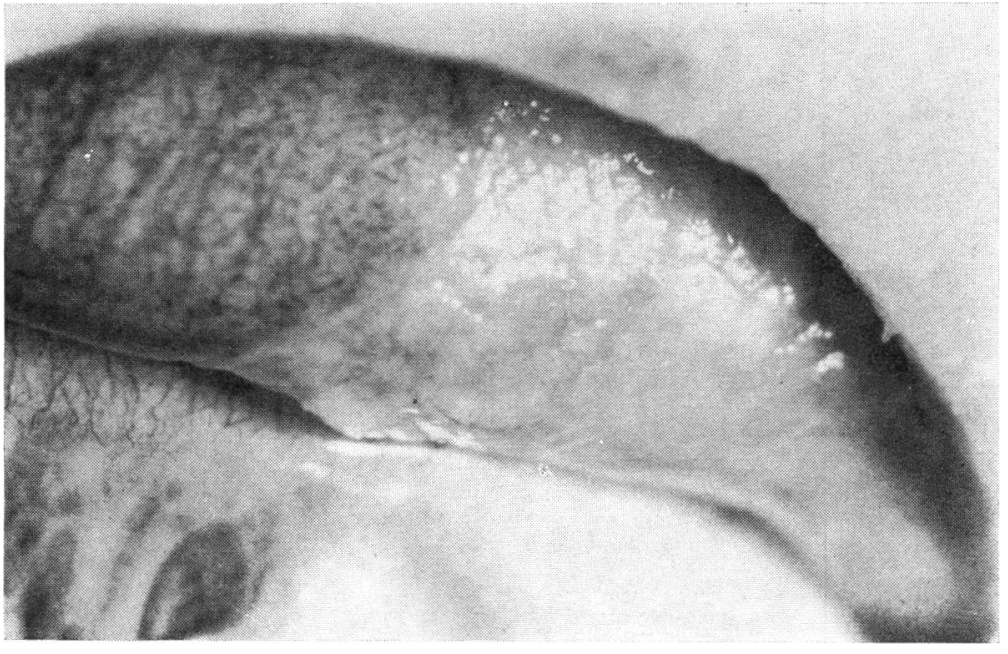

FIG. 3 Keratin plaque on upper tarsal conjunctiva 


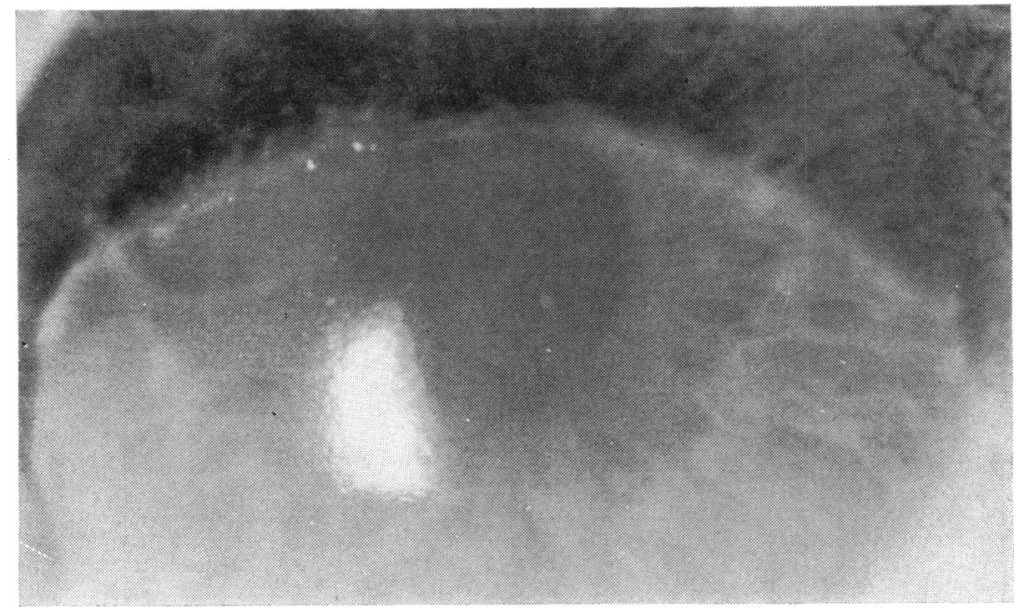

FIG. 4 Extensive corneal erosion

followed in II eyes by corneal erosion. In four eyes the erosion increased over four weeks to produce total corneal epithelial loss. Epithelial regrowth occurred in some eyes and was sometimes accompanied by wedge-shaped patches of conjunctival epithelium (Fig. 5) which later came to resemble corneal epithelium.

Corneal ulceration. This occurred as a late complication (after two to nine months) in four eyes. In one eye it responded to medical treatment, but in another it perforated and the eye was lost. One eye was successfully treated by a corneal graft. The fourth patient died before observations could be completed.

Corneal sensitivity. This was reduced in 19 eyes, including those with total corneal_erosions.

\section{Uvea (Table IV)}

Iris atrophy was a late sequel in three eyes after eight weeks. There was partial loss of the pigment epithelium, visible on transillumination. Rubeosis iridis occurred in one eye (see 'Intraocular pressure').

\section{Lens (Table IV)}

Radiation cataracts developed in II eyes and presented between 34 weeks and 19 months, most commonly between seven and 12 months. All those presenting after one year had not been examined between 12 months and the time of presentation. The earliest changes were often identified from the slit-image photographs. The cataracts consisted of fine granular and cystic material in the posterior subcapsular region of the lens (Fig. 6). In the less affected eyes the changes

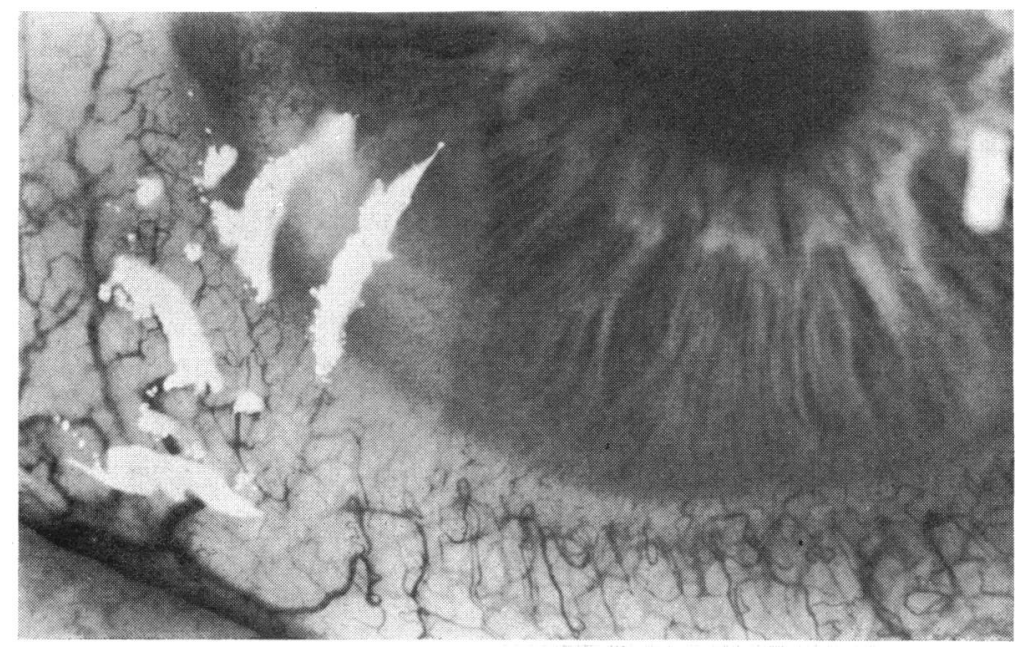

FIG. 5 Wedge-shaped patch of conjunctival epithelium is seen on cornea after healing of corneal erosion. Telangiectasia of bulbar conjunctiva 
Table IV Percentage incidence and nature of signs occurring in the uveal tract, lens, and retina related to radiation dose

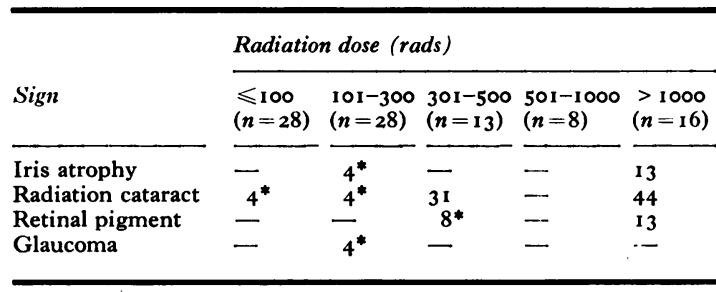

*Only one eye affected

were confined to the posterior pole, but in the three more severely affected there was thinning of the anterior subcapsular clear zone with some fine granular deposits arranged in radial lines in the equatorial periphery of this zone. In three eyes the posterior subcapsular opacities increased in density to the point where cataract extraction was indicated. Cataract extractions were uncomplicated in these cases. In three eyes mature cataracts developed rapidly in association with penetrating corneal ulcers. This occurred at seven months in one eye and at 15 months in the other.

\section{Retina (Table IV)}

Pigmentary retinopathy with a few microaneurysms was observed in three eyes at seven months. There was a fine scattering of pigment around the posterior pole, but normal electro-oculograms showed that there was no widespread disturbance of the retinal pigment epithelium. Central retinal artery occlusion occurred in one eye at 30 months. This eye had received 1252 rads.

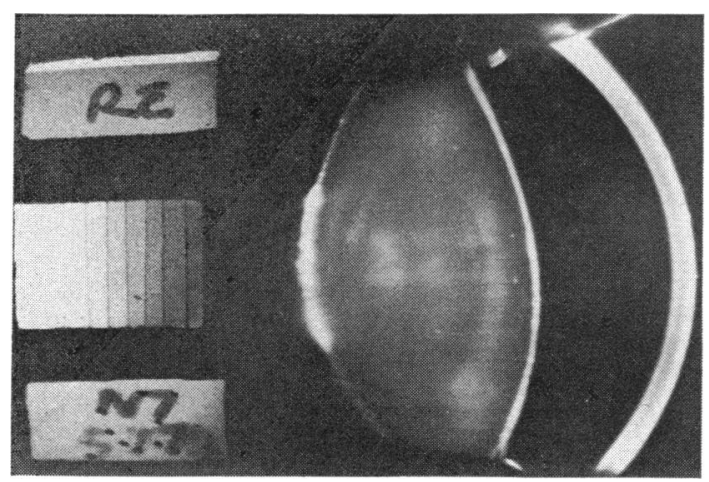

FIG. 6 Slit-image picture of lens showing developing posterior subcapsular cataract, absent anterior subcapsular clear zone, and fine anterior subcapsular cataract forming

\section{Intraocular pressure (Table IV)}

Reduction in intraocular pressure occurred in nine eyes after 29 days. Two recovered normal levels after I I weeks, but the other seven remained low. In one patient the final figure was significantly low at $6 \mathrm{mmHg}$. One eye developed absolute glaucoma in association with rubeosis iridis.

\section{Loss of vision or loss of eye}

Five eyes either lost all useful vision or became damaged beyond hope of recovery. With the exception of the glaucomatous eye ( 325 rads) and the eye with central retinal artery occlusion ( 1252 rads), loss of sight occurred only at doses greater than 1500 rads. In these eyes the sight was lost as a result of corneal ulceration and perforation due to corneal necrosis, and self-induced mechanical damage may have contributed in one of these cases in which the cornea was anaesthetic.

\section{Discussion}

Several papers, mainly American in the r950s, have reported the effects of neutron irradiation resulting from cyclotron accidents (Ham, I953; Haye, Mathé, Jammet and Pendic, I970); from chronic exposure in cyclotron workers (Ableson and Kruger, 1949; Dollfus, 1950); and from atom bomb explosion (Flick, 1948; Cogan, Martin, and Kimura, 1949; Cogan, Martin, and Ikui, 1950; Kimura and Ikui, I95I; Ham, 1953).

We know of none on the effects on the human eye of deliberate clinical exposure. Deliberate exposure has been confined to animal experimentation (Krause and Bond, I95I; Cogan, Goff, and Graves, I952; Moses, Linn, and Allen, 1953; Haye, Legeay, Bazin, and Quechon, 1970).

The relevance of the literature to the present study is not easy to assess. The type of radiation is not identical and the significance of the dose is uncertain. In accidental exposures the doses are necessarily vague and in animal experiments, where the doses are monitored, the relevance of the findings in an infant animal to the treatment of adult humans is questionable. Nevertheless, the literature is useful in describing the clinical features to be expected, particularly those of cataract. The histology of neutron cataract is described and the mechanism of its formation suggested. The animal experiments, in particular those of Krause and Bond (195I) and Cogan and others (1952), suggest that neutrons are more cataractogenic per unit energy than $x$ rays, and we expected that cataract would be the chief complication of neutron therapy. This proved not to be the case.

Kimura and Ikui (195I) and Cogan and Donaldson (1952) described doughnut-shaped posterior 
cortical cataracts in patients exposed to atom bomb irradiation. Histological examination showed granular material at the posterior pole and abnormal equatorial cells. In our study single-layered opacities occurred in the posterior subcapsular region and doughnut shapes were not seen. There were changes in the anterior subcapsular region, with obliteration of the subcapsular clear zone, followed by subcapsular cataract. This has been seen in cataracts from other causes (Brown and Tripathi, 1974). The opacities consist initially of a fine granular and cystic material in the lens periphery which is seen to move towards the poles, especially the posterior pole, on sequential observations. These observations support the view that it is the lens epithelium that is most sensitive to neutron irradiation, as suggested by Kimura and Ikui (195I), and to $x$ irradiation, as suggested by Grzedzielski (r935), Okusawa (r933), and Leinfelder and Kerr (1936).

\section{OTHER OCULAR EFFECTS}

The literature on neutron radiation is concerned mainly with cataract. In our study we found significant changes in eyelids, conjunctiva, and cornea. Such changes also occur in $x$ irradiation (DukeElder, 1954; MacFaul and Bedford, 1970; Merriam, Szechter, and Focht, 1972). We considered the temporary dysfunction in the eyelids of our patients to be due to vessel damage, with resultant erythema and oedema, and to damage to epithelial structures, causing epilation and meibomian gland obliteration. This was followed either by resolution with clinical recovery or fibrosis with resultant permanent dysfunction, including meibomian obliteration, ectropion, lacrimal punctal stenosis, and persistent oedema.

The lacrimal apparatus was affected by both epiphora and dry eyes. Epiphora was accounted for by punctal stenosis, naso-lacrimal duct obstruction, and reflex increase in tear production in response to corneal irritation. Keratoconjunctivitis sicca, which occurred in the more severely irradiated eyes, may be due to reduced tear secretion either as a result of destruction of the ductules of the lacrimal glands passing through cicatrization in the conjunctiva or as a result of destruction of the gland itself or of the accessory glands.

Abnormalities in the quality of the tears were also found. They were less able to wet the cornea on blinking and the precorneal tear film tended to dry between blinks-which was attributable in part to meibomian gland destruction with the resultant loss of the oily layer of the tear film. The particulate matter in the tear film consisted of leucocytes and erythrocytes which had probably entered the tears by diapedesis through the damaged vessel walls. We attributed the excess mucus sometimes seen soon after treatment to irritation of the goblet cells of the conjunctiva, and it may have been due to a goblet cell hyperplasia.

The conjunctival erythema and chemosis either resolved or went on to telangiectasia and persistent oedema. The oedema was probably due initially to an increased production of extracellular fluid from the dilated capillaries and later, when the vascularity had diminished, to reduced clearance of extracellular fluid by defective lymphatics. In severe cases there was epithelial loss, which was followed by conjunctival contracture with scarring and by invasion of the conjunctiva by squamous keratinizing epithelium from the lids.

\section{CORNEA}

The corneal epithelium was partially or, rarely, completely destroyed. This was probably due initially to radiation and the alteration in corneal environment caused by lid ectropion with exposure, and then keratin plaques and abnormalities of the tear film contributed to its persistence. The similar effects of $x$ irradiation directly upon the epithelium and through diminished tear secretion have been described by MacFaul and Bedford (1970), and Maumenee (1956) described the abrasive effect on the cornea of keratin plaques on the tarsal conjunctiva.

Corneal sensitivity was affected at the time of epithelial loss, after which sensitivity usually returned. In this respect neutron radiation appears to be less damaging than $x$ irradiation, which commonly significantly affects corneal sensation (MacFaul and Bedford, i970). The corneal stroma seems relatively resistant to neutrons but we attributed the severe late ulceration in three eyes to corneal necrosis. This is a well recognized late complication of $x$ irradiation (Blodi, r 958; Linnell and Wolter, r967; MacFaul and Bedford, I970; Merriam and others, I972) and after radium application (Martin, I 936). We did not see stromal vascularization, which may follow $x$ irradiation (Blodi, I958). The corneal endothelium seemed resistant to the dose of neutrons used and stromal oedema was seen only at the time of epithelial loss. Once corneal epithelial healing had occurred good vision returned and persistent oedema, which may follow $x$ irradiation (Blodi, 1958), did not occur.

UVEA

The uvea seems relatively resistant to neutron irradiation. Iris atrophy, a recognized effect of $x$ irradiation (Benedict, Christenberry, and Upton, I955), occurred but did not cause dysfunction. 
The intraocular pressure tended to fall, suggesting dysfunction of the ciliary body and permanent damage to it in patients in whom pressure remained low. There was no disability attributable to the low pressure. Rubeosis iridis associated with glaucoma is a recognized complication of $x$ irradiation (Jones, 1958; Bedford, 1966) and was seen in one neutron-irradiated eye.

\section{RETINA}

The retina seems resistant to neutron therapy. The changes in visual acuity could be accounted for by changes in the anterior segment. The minor pigmentary disturbance seen in three eyes was not associated with electroretinographic change, which is recognized in $x$ irradiation (Baily and Noell, 1958; Noell, 1962; Lipetz, 1962). Radiation retinopathy with haemorrhages and exudates is known to result from cobalt plaque application to the eye (Cibis and Brown, 1955; MacFaul and Bedford, 1970; Hayreh, 1970) and is reported after intensive $x$ irradiation in man (Chee, 1968; Billson, Yeung, and Crock, 1969; MacFaul and Bedford, 1970) and in experimental animals (Cibis, Noell, and Eichel, 1955). In the present study only two eyes showed small numbers of microaneurysm.

\section{DOSE RESPONSE RELATIONSHIP TO CLINICAL EFFECT}

Tables I-IV show the incidence of symptoms and signs related to neutron dosage. In another communication (Brown and others, 1976) we related dosage to clinical effect in a smaller number of eyes. We found no significant differences in the 93 eyes reported here. Our results, as reported earlier, indicate that doses up to about 80 rads produce no recognizable effect. Doses of 85 to 220 rads produce slight transient disturbance of vision and irritation followed by complete resolution. Doses of 220 to 860 rads produce a moderate disturbance of vision and discomfort with incomplete resolution resulting in a slight, permanent reduction in vision. Doses of 860 to 1510 rads commonly produce a severe clinical effect with significant reduction in vision and little resolution. Most of the patients in this group have persistently poor vision, but in some this is remedied by cataract extraction. A few patients even in the upper range of this group are symptom-free after I 8 months. Doses in excess of 1510 cause ocular destruction and no useful vision is retained.

\section{ANALYSIS OF ERRORS}

There were only a few eyes in each dosage group, which makes it difficult to draw conclusions from the percentage incidence of signs and symptoms. The tendency was for the incidence of a symptom or sign to increase with dosage, with the following exceptions. In the group of patients where the dose was more than 1000 rads the incidence of facial and lid erythema, mucopurulent discharge, and conjunctival injection seemed to be low. These are early signs and not all the patients in that group were seen at the earliest stages.

The group 501-1000 rads consisted of eight patients and it was unfortunate that this group comprised some of the most sparsely documented patients by reason of irregular attendances, etc. Thus any apparent anomaly in this group must be attributed to these factors. In the group $\leqslant 100$ rads only one eye had chemosis, injection, and mucopurulent discharge. These signs were due to incidental conjunctivitis and not to radiation. In one eye with reduced corneal sensation in this group the loss of sensation was minimal.

There are some doubts about the accuracy of the dosages of radiation stated in this study, for the following reasons:

I. The lower the estimated dose the higher the possible error. Thus a stated dose of 50 rads may be \pm 10 rads in error, but, for example, a dose of 680 rads may be \pm 30 rads, a lower percentage error.

2. An eye placed at the edge of the field will receive a variation of dose across the eye. When measuring doses across the eye by aluminium activation, pellets of aluminium may also be on the edge of the field. An incorrect estimate of dose may be obtained if only part of the pellet is irradiated. In cases where this was thought to have occurred the maximum possible dose was estimated.

3. The error in calculating the doses received was of the order of 5 per cent.

\section{ERRORS IN INCIDENCE OF SIGNS AND SYMPTOMS}

The timing of follow-up varied between patients. Some were not examined until after the start of radiotherapy and there were occasional lapses in regular follow-up owing to patients not being able to attend. Thus some early signs might have been missed. Some patients were not followed-up for more than a few weeks for various reasons, and so the incidence of late complications may well be higher than that given.

\section{Summary}

This study of 93 eyes receiving neutron irradiation establishes the character of the ophthalmic complications of neutron treatment. Significant changes are produced in the eyelids, conjunctiva, and 
cornea, but the production of cataract is relatively unimportant. No reaction was seen after neutron treatment that had not already been seen after $x$ or gamma radiation. That the unavoidable damage is similar to that reported with other forms of radiation, and not worse, is an important finding in view of the statistically significant benefit of neutron treatment to patients in a controlled clinical trial of advanced tumours of the head and neck (Catterall and others, 1975). The observations indicate that the improved cure rates with neutrons are not obtained at the expense of inflicting greater damage to normal structures. This investigation has also shown that the neutrono effects of treating these very extensive tumours are acceptable and that, with carefully measured doses, they are predictable.

The dose-response relationship in categories of clinical effect for a smaller series of patients, $\frac{\bar{D}}{\bar{D}}$ reported in Table I of our preliminary communi- $-\frac{\Phi}{\Omega}$ cation (Brown and others, 1976), is confirmed.

We acknowledge the help given by the Medical Research Council in a grant which made this work possible, both $\vec{\omega}$ in the supply of equipment and in the payment of the salary of one of us (JR).

\section{References}

ABLeSON, P. H., and KRUGER, P. G. (1949) Science, I10, 655 BAILY, N. A., and NOELL, w. K. (1958) Radiat. Res., 9, 459 BEDFORD, M. A. (1966) Proc. roy. Soc. Med., 59, 529 BENEDICT, w. H., CHRISTENBERRY, K. W., and UPTON, A. c. (1955) Amer. F. Ophthal., 40, 163

BILlSON, F. A., YEUNG, J., and CROCK, G. W. (1969) Fundus angiography in radiation damage to the visual path,

In 'Proceedings International Symposium Fluorescein Angiography, Albi', p. 637 BLodi, F. (1958) Trans. Amer. ophthal. Soc., 56, 413 BROWN, N. (1972) Trans. ophthal. Soc. U.K., 92, 303

-, Roth, J., CATterall, M., and Beal, A. (1976) Brit. F. Ophthal., 60 (in press)

- , and TrIPATHI, R. C. (1974) Trans. ophthal. Soc. U.K., 94, 29

CATTERALl, M., SUTHERLAND, I., and BEWLEy, D. K. (1975) Brit. med. f., 2, 653

$\longrightarrow$, and VONBERG, D. D. (1974) Ibid., 3, 137

CHEE, P. H. Y. (1968) Amer. F. Ophthal., 66, 860

CIBIS, P. A., and BROWN, D. V. L. (1955) Ibid., 40, 84

, NOELL, w. K., and EICHEL, B. (1955) Arch. Ophthal.; 53, $65 \mathrm{I}$

COGAN, D. G., and DONALDSON, D. D. (1952) Ibid., 47, 55

, GOFF, J. L., and GRAVES, E. (1952) Ibid., 47, 584

-, martin, S. F., and IKUI, H. (1950) Trans. Amer. ophthal. Soc., 48, 62

$\longrightarrow$, $\longrightarrow$, and KIMURA, S. J. (1949) Science, 110, 654

dollfus, M. A. (1950) Bull. Soc. Ophtal. Paris, 5, 459

DUKE-ELDER, S. (1954) 'Textbook of Ophthalmology', vol VI, p. 6538. Kimpton, London

FLICK, J. J. (1948) Amer. F. Ophthal., 31, 37

GRZEDZIELSKi, J. (1935) Klin. Mbl. Augenheilk., 95, 360

HAM, w. T. (1953) Arch. Ophthal., 50,618

haye, C., Legeay, G., bazin, J. P., and Quechon, h. (I970) Ann. Oculist. (Paris), 203, 749

-, Mathé, G., Jammet, H., and PENdic, B. (1970) Arch. Ophtal. (Paris), 30, 567

HAYREH, S. S. (1970) Brit. F. Ophthal., 54, 705

JONES, R. F. (1958) Ibid., 42, 636

Kimura, s., and IKUI, H. (1951) Amer. F. Ophthal., 34, 81 I

KRAUSE, A. C., and BOND, J. C. (195I) Ibid., 34, 25

LEINFELDER, P., and KERR, H. (1936) Ibid., 19, 739

LINNELl, P. C., and wolter, J. R. (1967) Eye, Ear, Nose, Thr. Monthly, 46, 328

LIPETZ, L. (1962) Effects of ionizing radiation on the visual function. In 'Response of the Nervous System to

Ionizing Radiation', ed. J. T. Haley, p. 533. Academic Press, London and New York

MACFAUl, P. A., and BEDFORD, M. A. (1970) Brit. $\mathcal{Y}$. Ophthal., 54, 237

MARTIN, P. (1936) Trans. ophthal. Soc. U.K., 56, 87

MAUMENEe, A. E. (1956) Amer. F. Ophthal., 4r, 477

MERRIAM, G. R., SZECHTER, A., and FOCHT, E. F. (1972) Front. Radiat. Ther. Oncol., 6, 346

moses, C., LiNn, J. G., and Allen, A. J. (1953) Arch. Ophthal., 50, 609

NOELL, w. K. (1962) $X$-irradiation studies on the mammalian retina. In 'Response of the Nervous System to

Ionizing Radiation', ed. J. T. Haley, p. 543. Academic Press, New York and London

okuSawa, T. (1933) Acta Soc. Ophthal. jap., 37, 814 